climate change and are a potential future consequence of presentday climate warming. Conversely, alpine populations also impacted their own environment, at least since the Bronze Age, through changes in land-use resulting in increasing sediment fluxes, deliveries to lake basins and changes in the flora and fauna.

The complexity of the retroactions between humans, climate and natural systems makes it difficult to disentangle the human and climate fingerprints from the majority of the natural archive records. This points to the necessity of increasing collaboration between archaeologists and paleo-environmentalists and to work with the largest proxy panoply. Consequently, it was decided to continue this regional, pluridisciplinary approach and the workshop gave birth to the "ClimAlp' Initiative", whose objective is to facilitate exchanges within the community-mainly via a list-server-the construction of a database and the support of further meetings.
Marc Desmet, Fabien Arnaud

Université de Savoie Le Bourget du Lac, France

marc.desmet@univ-savoie.fr

MARIE-Antoinette MöLIÈres

LGGE, Saint-Martin d'Heres, France

Emanuel Chapron

Geological Institute, ETH Zürich, Switzerland

\section{Climalp members}

www.institut-montagne.org

\title{
Indian Monsoon and Holocene Climate Variability
}

\section{BangaloRe, INDIA, 17-18 May 2004}

The Geological Society of India (Dr. B.P. Radhakrishna, President) organized an International Workshop from 17-18 May 2004 in Bangalore, India, sponsored by PAGES, the Department of Ocean Development (New Delhi), the Department of Science and Technology (New Delhi), and the Indian Space Research Organization (Bangalore). The workshop was well organized by $\mathrm{R}$. Shankar from Mangalore University and centered around the following three themes: Holocene climate series from marine records (Arabian Sea and Bay of Bengal; 7 invited talks); continental records (lake/tank sediments, stalagmites, peats, river floods; 9 invited talks); and monsoonal rainfall variability and prediction (3 invited talks). About 55 Indian scientists and 6 scientists from Bangladesh, Germany, Sweden and the USA attended the meeting. The wide opportunity for informal discussions between the scientists during tea breaks, meals and poster sessions, the pleasant ambience of the conference hall and guesthouse of the National Institute for Advanced Studies (NIAS), set amidst a peaceful flowery park, and the exquisite South Indian cuisine, as well as a cultural program featuring expressive dances with ancient Hindu religious themes made this workshop a memorable experience for all participants.

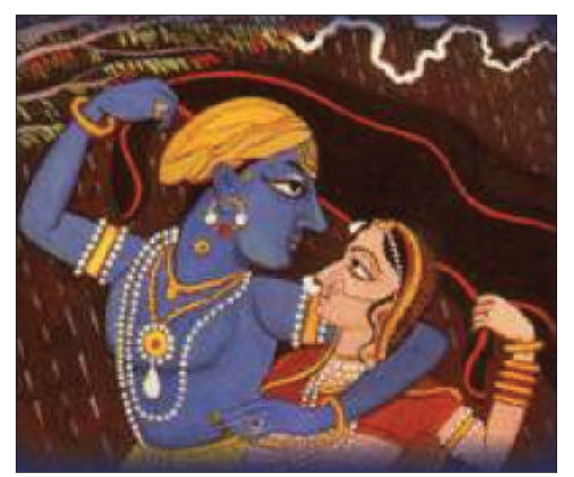

Fig. 1: Indian miniature showing a male Monsoon donating rain and fertility, as a symbol of life and love, to a voluptuous woman.

Highlights were the talks on "The Indian Monsoon as a Component of the Climate System during the Holocene" (R.R. Kelkar), "Has the Winter and Spring Rain over NW India and Pakistan changed during the Holocene?"(M. Staubwasser), "Luminescence Chronometry of Land Records and Palaeomonsoon Reconstruction: Applications and Implications" (A.K. Singhvi), "Summer Monsoon Rainfall Variability Recorded in Stalagmites from Oman and Yemen" (D. Fleitmann), and "Holocene Precipitation and Monsoon Theories" (J. Srinivasan). After peer review, papers will be published in a Special Issue of the Journal of the Geological Society of India.

During the concluding session, achievements and new avenues of research were outlined. The need for closer collaboration between the various Indian working groups and the Department of Science and Technology was stressed, as well as the need for improved cooperation between Indian scientific institutions and the international community (which in the marine realm is still hampered by the inaccessibility of the Indian EEZ to non-Indian research vessels).

Once again, the need for more long-term, high-resolution marine, coral and continental records on a decadal (or even sub-decadal) level was emphasized. New dating techniques should be developed and applied (e.g., luminescence chronometry) and existing ones, such as ${ }^{14} \mathrm{C}$ dating, calibrated with new reservoir ages.

Major open questions include:

How can we define "monsoon intensity" (wind strength, rainfall, temperature)?

Can we define better proxies for winter versus summer monsoon, as well as for sea surface salinity?

Can we link terrestrial and marine archives?

\section{ULRICH VON RAD \\ Hannover, Germany \\ u.vonrad@t-online.de}




\section{PAN Africa START-PAGES-INQUA Workshop on African Paleoenvironments}

Nairobi, KenYa, 19-21 July 2004

After the successful workshop on High Latitude Paleoenvironments held in Moscow 2001, PAGES, START and INQUA helped to organize a workshop on African paleoenvironments in Nairobi, Kenya from 19-21 July 2004. The local organizing committee, the Pan-African START Secretariat, organized the event perfectly and provided a nice venue in the City Center of Nairobi.

One of the major goals was to facilitate a closer interaction between the African paleocommunity and an integration of African research into the international community. As shown by the different presentations, ranging from morphological - hydrological studies in Malawi to Isotope modeling in Ethiopian Lakes, from human impacts on East African lake ecosystems to paleo reconstructions from ocean sediments off Africa, this continent provides a huge and impressive amount of paleo information. After 10 years, the PAGES IDEAL Programme (Past Global Changes - International Decade on East African Lakes) is coming to synthesis. As reported by Prof.

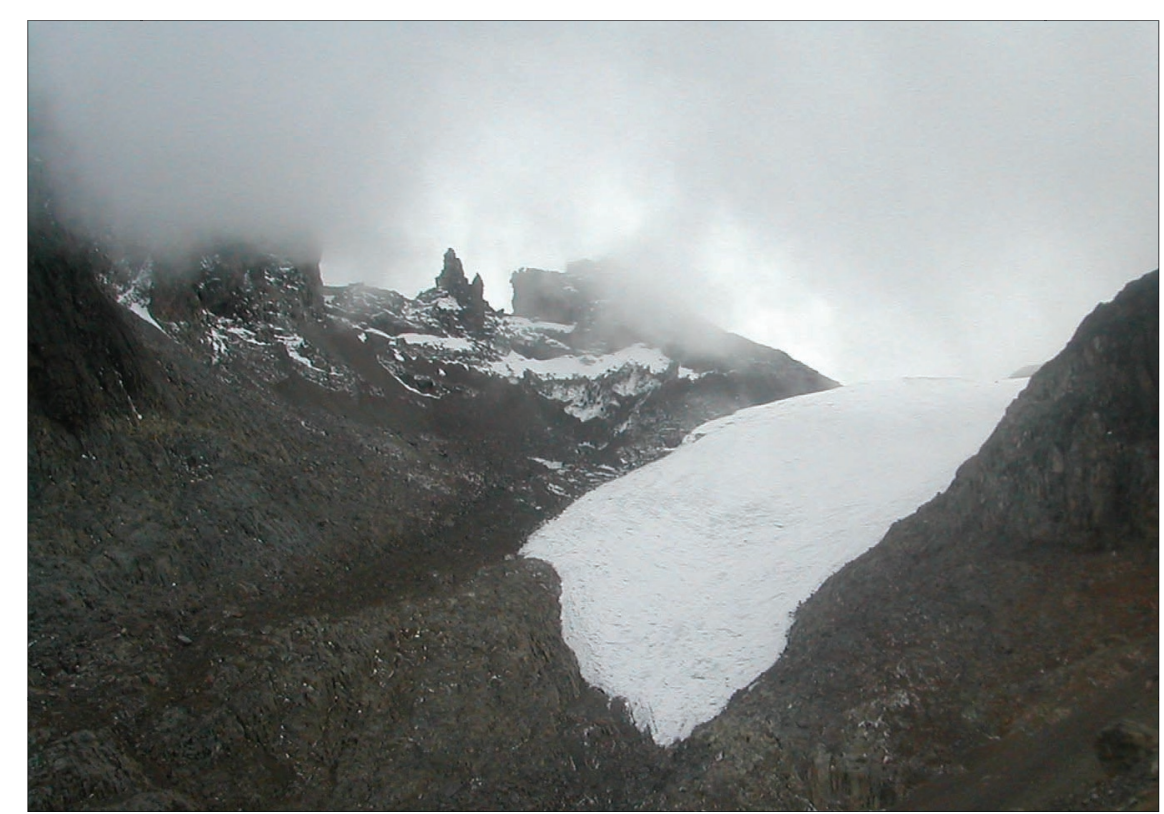

Fig. 1: Climate Change also dramatically affects the African high altitude environments. View to the remaining Lewis Glacier on Mount Kenya in 2004. (Photo: Jérôme Chappellaz)

Johnson, Lake Malawi provides a unique archive spanning back probably 1 million years. Those Lake sediments provide evidence of changing tropical atmospheric circulation south of the Equator. Similar results were presented by $M$. Umer and D. Legesse from the Ethiopian Lakes north of the equator. Changing atmospheric circulation influenced strongly the ecosystems in the past and has also had a recent impact on those densely populated East African regions (see Fig. 1). Under economic and societal pressure, the East African Lake ecosystems suffer especially due to intensified land and water use. Changing lake levels, enhanced pollution and overfishing have drastically affected these unique ecosystems. Future developments must have a strong and controlled management if these fantastic ecosystems are to exist in the future. Dramatic human impact and related effects on Lake Naivasha were presented as an example for the vulnerable region by $\mathrm{G}$. Owiti from the $\mathrm{Ke}$ nyan Wildlife Service. West African presentations concentrated on the human impact on coastal environments in Nigeria and changes in recent precipitation patterns.

After two days of presentations, a plenary discussion enabled participants to focus on educational and international collaborations. African research needs a stronger interaction with the international community, better communication and help gathering financial resources. The Senior Scientific Officer of the Pan-African START Secretariat, Dr. Daniel Olago, guided the participants in a discussion to focus future research direction, following the results that had emerged from the previous contributions. Education and future research in Africa must include a better integration of the local research institutes and also reach topics and scientists besides the "hot" research issues, in order to provide help for a broader integration of African scientists.

It is the aim of ongoing PAGES collaboration to involve African scientists in international research, to produce a special journal issue in order to hopefully reproduce the success of the Russian workshop example. The Nairobi conference showed how international funding and networking may be used to boost essential scientific development and was greatly appreciated by local scientists.

Further Information on African Paleoscience is available at the Pan African Start Secretariat (PASS):

Pan-African START Secretariat University of Nairobi Dept. of Geology, Nairobi Kenya pass@uonbi.ac.ke http://pass.uonbi.ac.ke http://wdc.uonbi.ac.ke

Christoph Kull PAGES IPO, Bern, Switzerland kull@pages.unibe.ch 